\title{
artigo
}

Pinto, C.C.; Amin da Silva, B.L.; Santos, E.S.A.; Oliveira, S.R.M.; Amorim, M.T.; Amaro, B.O.; Gomes, E.P.A.; Casseb, S.M.M.;

Perfil Epidemiológico da Raiva Humana na Região Norte do Estado do Pará durante o período de 2000 a 2019

\section{Perfil Epidemiológico da Raiva Humana na Região Norte do Estado do Pará durante o período de 2000 a 2019}

Epidemiological Profile of Human Rabies in the Northern Region of the State of Pará during the period from 20002019 Perfil epidemiológico de la rabia humana en la región norte del estado de Pará durante el período 2000 a 2019

\section{RESUMO}

Objetivou-se realizar uma análise do número de casos notificados do vírus da raiva humana na região Norte do Brasil no período de 2000 a 2019. Trata-se de estudo observacional, de base epidemiológica, com base em dados do SINAN no período de 2000 a 2019. Foram elaborados mapas e gráficos para análise espacial do número de casos. Observou-se, no período de 2000 a 2006, 61 casos. Sendo que, nos anos de 2004 e 2005 ocorreram alguns surtos. No período de 2006 a 2015 não houveram notificações. Já nos anos de 2016 a 2019 foram notificados 16 casos. De 2000 a 2019 foram registrados 316 casos no país. A região Nordeste obteve maior número de casos no Brasil no período estudado ( $N=204 ; 65 \%$ ), em seguida a região Norte ( $N=77$; 24\%). Assim, a otimização do controle da doença, pela adoção de recursos regulatórios, destaca-se como a melhor medida para o controle da raiva.

DESCRITORES: Raiva Humana; Epidemiologia; Saúde Coletiva; Saúde Pública.

\section{ABSTRACT}

The objective was to carry out an analysis of the number of notified cases of the human rabies virus in the northern region of Brazil in the period from 2000 to 2019 . This is an observational study, based on epidemiology, based on data from SINAN in the period from 2000 to 2019. 2019. Maps and graphs were prepared for spatial analysis of the number of cases. In the period from 2000 to 2006, 61 cases were observed. Since, in 2004 and 2005 there were some outbreaks. In the period from 2006 to 2015 there were no notifications. In the years 2016 to 2019, 16 cases were reported. From 2000 to 2019 , 316 cases were registered in the country. The Northeast region had the highest number of cases in Brazil during the study period ( $N=204 ; 65 \%$ ), followed by the North region ( $N=77 ; 24 \%$ ). Thus, the optimization of disease control, through the adoption of regulatory resources, stands out as the best measure for the control of rabies.

DESCRIPTORS: Human Anger, Epidemiology, Collective Health, Public Health.

\section{RESUMEN}

El objetivo fue realizar un análisis del número de casos notificados del virus de la rabia humana en la región norte de Brasil en el período 2000 a 2019. Se trata de un estudio observacional, basado en la epidemiología, con base en datos del SINAN en el período de 2000 a 2019. 2019. Se elaboraron mapas y gráficos para el análisis espacial del número de casos. En el período de 2000 a 2006, se observaron 61 casos. En 2004, se produjeron algunos brotes. En el período de 2006 a 2015 no hubo notificaciones. En los años 2016 a 2019 se notificaron 16 casos. De 2000 a 2019, se registraron 316 casos en el país. La región Nordeste tuvo el mayor número de casos en Brasil en el período estudiado ( $N=204 ; 65 \%$ ), seguida de la región Norte (N = 77; 24\%). Así, la optimización del control de enfermedades, mediante la adopción de recursos regulatorios, se destaca como la mejor medida para el control de la rabia.

DESCRIPTORES: Rabia Humana, Epidemiología, Región Norte, Salud Pública.

RECEBIDO EM: 19/04/2021 APROVADO EM: 25/05/2021

\section{Caroline Carvalho Pinto}

Biomédica pelo Centro Universitário Fibra, Mestranda em Virologia pelo Instituto Evandro Chagas.

ORCID: 0000-0002-7691-3725

\section{Bruna Labibe Amin da Silva}

Biomédica pelo Centro Universitário Fibra;.

ORCID: 0000-0002-1731-2962 


\section{Evelyn Samara Amaral dos Santos}

Biomédica pelo Centro Universitário Fibra.

ORCID: 0000-0002-5887-7580

\section{Suzana Ribeiro de Melo Oliveira}

Biomédica pelo Centro Universitário Fibra, Mestre em Virologia pelo Instituto Evandro Chagas.

ORCID: 0000-0002-4077-7178

\section{Murilo Tavares Amorim}

Biomédico pelo Centro Universitário Fibra, Mestrando em Biologia de Agentes Infecciosos e Parasitários da Universidade Federal do Pará. ORCID: 0000-0002-9769-2183

\section{Beatriz Oliveira Amaro}

Biomédica pela Escola Superior da Amazônia, Mestranda em Epidemiologia e Vigilância em Saúde pelo Instituto Evandro Chagas. ORCID: 0000-0002-8738-6991

\section{Elisa Paula Amaral Gomes}

Graduanda em Biomedicina pelo Centro Universitário Fibra.

ORCID: 0000-0002-5887-7580

\section{Samir Moraes Mansour Casseb}

Biólogo, Mestre em Genética e Biologia Molecular pela Universidade Federal do Pará, Doutor em Virologia pelo Instituto Evandro Chagas e Pesquisador Adjunto da Seção de Patologia do Instituto Evandro Chagas.

ORCID: 0000-0002-7419-3381

\section{INTRODUÇÃO}

A Raiva Humana é uma encefalite viral aguda ocasionada por meio de um vírus do gênero Lyssavirus, da Família Rhabdoviridae. O paciente infectado pode apresentar quadro neurológico agudo (encefalite), que apresenta formas de hiperatividade, seguido de síndrome paralítica com progressão para coma, sem possibilidade de diagnóstico laboratorial, mas com antecedente de exposição à provável fonte de infecção ${ }^{1}$.

O gênero Lyssavirus apresenta 8 genótipos, sendo que o genótipo 1 - Rabies vírus (RABV), o único presente na América Latina e no Brasil, pode ser expresso, de acordo com o perfil, em 12 variantes antigênicas, conforme seus respectivos hospedeiros naturais (terrestres ou aéreos). No Brasil, foram encontradas 7 variantes antigênicas: variantes 1 e 2, isoladas dos cães; variante 3 , de morcego hematófago Desmodus rotundus; e variantes 4 e 6 , de morcegos insetívoros Tadarida brasiliensis e Lasiurus cinereus ${ }^{1}$.

Os mamíferos selvagens servem como um grande e incontrolável reservatório da raiva silvestre, que é uma ameaça cada vez
No Brasil, foram

encontradas

7 variantes

antigênicas:

variantes 1 e 2 ,

isoladas dos cães;

variante 3 , de

morcego hematófago

Desmodus rotundus;

e variantes 4 e 6, de

morcegos insetívoros

Tadarida brasiliensis

e Lasiurus cinereus maior para o homem e para os animais domésticos em todo o mundo. Descreve-se uma hierarquia na susceptibilidade para as diferentes espécies de mamíferos selvagens, sendo as espécies mais afetadas: raposas, coiotes, chacais e lobos, nesta ordem. A raiva silvestre é caracterizada pelo envolvimento de uma ou mais espécies principais (pequenos carnívoros e mustelídeos), especialmente nas regiões onde este modelo permanece estável por muitos anos ${ }^{2,3}$.

No Brasil, país onde a raiva é enzoóti$\mathrm{ca}$, ocorrem todos os ciclos epidemiológicos, prevalecendo o ciclo da raiva rural. $\mathrm{O}$ morcego hematófago da espécie Desmodus rotundus, vulgarmente conhecido como "morcego-vampiro-comum," é o principal reservatório da raiva rural, por isso também chamada "raiva desmodina", na América Latina ${ }^{4}$. Ocorreu um aumento nas atividades de controle da raiva canina (1973), quando foi instituído no país o Programa Nacional de Profilaxia da Raiva Humana (PNPR), que buscou reduzir a doença em animais domésticos. As ações do PNPR foram se expandindo gradativamente até sua implantação ser concluída, em todo território nacional, em 1977. Essas ações foram fortalecidas quando, em 1983, a 
Organização Pan-Americana da Saúde (OPAS) desenvolveu o 'Plano de Ação para Eliminação da Raiva Urbana das Principais Cidades da América Latina', resultando no compromisso internacional da eliminação da raiva humana transmitida por cães nas Américas até $2012^{5,6,7 \mathrm{e} 8}$.

Devido ao alto grau de letalidade, a raiva humana torna-se um grave problema de saúde pública, tendo como áreas endêmicas as regióes Norte e Nordeste do País. Nos anos de 2004 e 2005, com a ocorrência de surtos de raiva humana nos estados do Pará e Maranhão, o morcego passou a ser o principal responsável pelos casos de raiva humana, com $86,5 \%$ dos casos nesses dois anos, ultrapassando os índices de transmissão canina? .

A Região Norte do Brasil engloba os estados de Acre, Amapá, Amazonas, Pará, Rondônia, Roraima e Tocantins. É marcada pelas suas peculiaridades, entre as quais se incluem a acentuada desigualdade socioeconômica e também o isolamento geográfico em relação às regiões mais desenvolvidas do país. Seus indicadores sociais estão entre os piores do Brasil, em contraste com o seu expressivo crescimento econômico e populacional, muito acima da média nacional. $\mathrm{O}$ meio de transporte comumente utilizado é o fluvial, e o tempo de viagem de um município a outro pode superar 15 dias, deixando muitas cidades isoladas geograficamente, e nas quais se observam altos índices de pobreza ${ }^{10}$. Este estudo tem como objetivo fazer uma análise do número de casos notificados do vírus da raiva humana na região Norte do Brasil no período de 2000 a 2019.

\section{MÉTODO}

Trata-se de um estudo observacional, transversal, retrospectivo, de base epidemiológica, sendo realizado por meio da investigação de estudos que retrata abordagens com ênfase na distribuição espacial da raiva humana na região Norte do Brasil, em comparativo à correlação dos dados de registro disponíveis de acesso público no SINAN disponibilizados no Departamento de Informática do Sistema

\section{O meio de}

transporte

comumente

utilizado é o fluvial,

e o tempo de viagem

de um município

a outro pode

superar 15 dias,

deixando muitas

cidades isoladas

geograficamente,

e nas quais se

observam altos

índices de pobreza.

Este estudo tem

como objetivo fazer

uma análise do

número de casos

notificados do vírus

da raiva humana

na região Norte do

Brasil no período de

2000 a 2019.
Único de Saúde (DATASUS) no período de 2000 a 2019, cuja distribuição de etapas de desenvolvimento, distingue-se em duas vertentes:

A primeira, tendo o seu delineamento relacionado a busca por estudos de metodologia aplicável ao tema proposto, em que promoveu-se a identificação da abordagem, sob o qual, pôde-se delinear que perspectiva seria executada a fim de estabelecer a proposta inicial de estudo; formulação da questão norteadora; elaboração dos critérios de inclusão e exclusão de artigos; construção de instrumentos para coleta de dados relevantes dos artigos encontrados; consulta e busca e seleção dos Descritores de busca nas bases de dados e plataformas de acesso; avaliação e análise dos artigos selecionados na pesquisa; escolha do produto teórico para apresentação do estudo; interpretação e discussão dos resultados obtidos.

A segunda, baseou-se na busca, identificação e registro dos casos notificados de raiva humana no período descrito, submetendo a busca aos determinantes de subdivisões baseadas em regiões. Os mapas com os dados epidemiológicos de cada região, foram feitos no programa QGSIS. Foi utilizado o programa Excel para tabulações de dados e construção de gráficos. Além disso, foi realizada porcentagem básica e média aritmética.

O levantamento dos estudos obtidos na literatura foi realizado no período de setembro a dezembro de 2020. As bases de dados selecionadas foram: Nature, Medical Literature Analysis and Retrieval System Online (Medline) e Scientific Electronic Library Online (SciELO). Optou-se por se ater a estudos publicados na língua inglesa e portuguesa. Os descritores selecionados foram: Raiva Humana, Epidemiologia, Saúde Coletiva e Saúde Pública. Privilegiou-se os artigos mais recentes, publicados nos últimos 10 anos, textos disponibilizados na íntegra e pesquisas classificadas como originais. Quanto ao levantamento dos dados, para a busca foram utilizados os filtros da plataforma SINAN, com base no período previamente estabelecido (2000-2019). Para o registro do 
objeto de estudo, utilizou-se o programa Microsoft Excel e os dados foram preparados para processamento global. Depois, os mapas foram construídos e delimitados com base na proposta do estudo por meio da utilização do programa QGSIS.

\section{RESULTADOS}

Na região Norte, foram 77 casos con-

Figura 1 - Distribuição espacial dos casos de raiva humana notificados ( $N=77$ ), Região Norte do Brasil, 2000-2019.

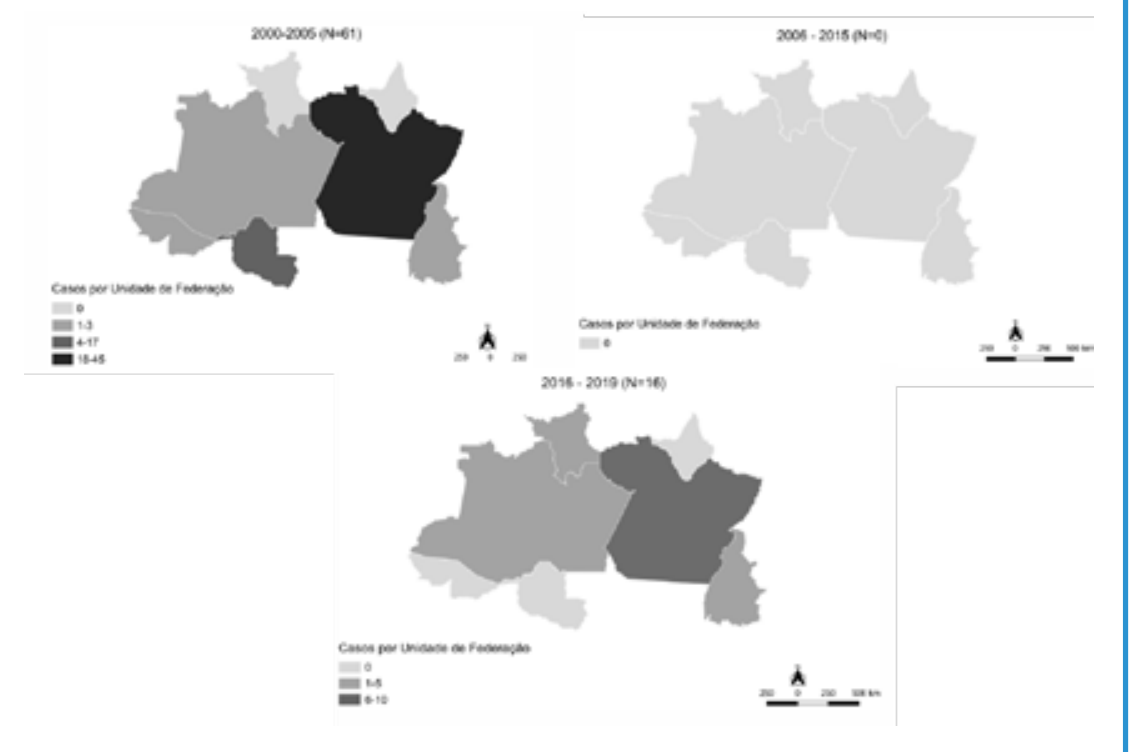

Fonte: Autoria Própria

\section{Figura 2: Distribuição das notificações de raiva humana no Brasil e nas regiões} brasileira, 2000 a 2019.

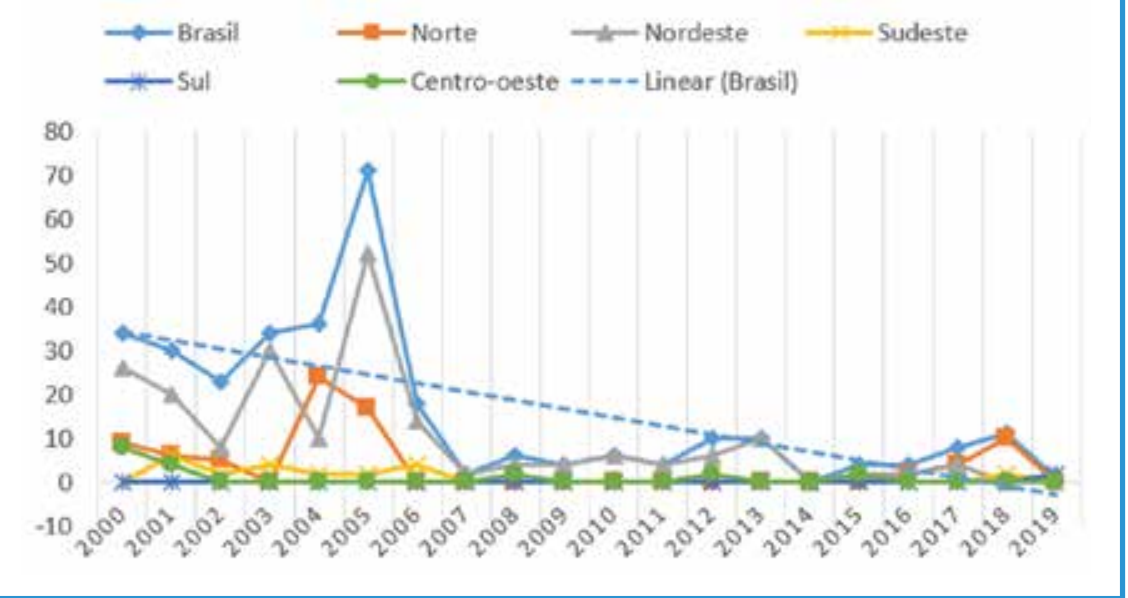

Fonte: Autoria Própria

firmados no período estudado, sendo que destes, 61 casos foram registrados entre os anos de 2000 a 2005 . Houve surto de casos de raiva humana nos anos de $2004 \mathrm{e}$ 2005 ocasionadas por morcegos hematófagos (figura 1) ultrapassando o número de transmissões caninas que até o momento era o maior responsável pelas notificações. Os surtos ocorreram no estado do Pará, acometendo as áreas rurais e ribeirisurto no estado do Pará, no município de soas (figura 1).

No Acre e Tocantins, houveram 3 notificações em ambas no total do período de 2000 a 2019. Em Roraima houve apenas 2 casos no total, este ocorreu no ano de 2016. No Amapá não houve registro de casos de Raiva humana no período estudado.

No período de 2000 a 2019 foram registrados 316 casos no país, uma média de 16 casos ao ano de raiva humano no Brasil, com predominância pelo sexo masculino e moradores da zona rural. A maior frequência de exposição foi por mordedura de animal, no caso cães e morcegos. Em relação ao número de notificações por região, figura 2 prevaleceu como o maior número de casos no período estudado, a região Nordeste $(\mathrm{N}=204 ; 65 \%)$, seguida pela região Norte $(\mathrm{N}=77 ; 24 \%)$, Sudeste $(\mathrm{N}=24 ; 8 \%)$, Centro-Oeste $(\mathrm{N}=18 ; 6 \%)$ e a região Sul $(\mathrm{N}=2 ; 1 \%)$. Observou-se que as maiorias dos casos ocorreram entre 2000 a 2008, apesar da diminuição linear dos casos de raiva humana no Brasil (figura 2), a região Norte e Nordeste apresentou maior fragilidade a surtos de casos.

\section{DISCUSSÃO}

O controle da raiva humana é possível, sobretudo nessas regiões isoladas e de elevada pobreza, diante do acesso à vacinação, que tem sido um dos principais meios de controle da doença no Brasil nos últimos anos. Existe uma certa dificuldade em promover as ações do PNPR, e, portanto, a baixa cobertura vacinal diante de um grande contingente de pessoas suscetíveis. 
É possível observar uma mudança no perfil epidemiológico no país, evidenciando assim, o aumento do ciclo aéreo silvestre e rural, sendo assim, existe uma maior dificuldade no seu controle.

A Região Norte foi a segunda região com mais notificações (77) no período estudado. A falta de informações, saneamento básico e uma estrutura inadequada de saúde, contribuíram para os surtos. O predomínio de casos na zona rural, provavelmente devido a surtos com exposição aos morcegos D. rotundus na Amazônia brasileira em 2006 e $2009^{11,12}$. Além disso, houve um crescente desmatamento nas regiões, os impactos desta atividade trouxeram os morcegos para mais perto das comunidades. Os principais fatores que contribuem para que a raiva no Brasil se dissemine ainda de forma insidiosa e preocupante nos herbívoros são: ocupação desordenada, caracterizada por macro modificaçôes ambientais, como desmatamento, construção de rodovias e de hidroelétricas, que alteraram o ambiente em que os morcegos viviam, obrigando-os a procurar novas áreas e outras fontes de alimentação ${ }^{13}$.

No Nordeste brasileiro a raiva é endêmica, sendo registrado casos de raiva humana em todas unidades federativas dessa ${ }^{14}$. Diante disso, foi possível observar que esta foi a região que mais possuiu casos de raiva humana nesses 20 anos no Brasil. Para que o controle da raiva dos herbívoros seja efetivo, é importante que o Serviço Estadual de Defesa Sanitária Animal mantenha uma rotina de cadastro dos refúgios/abrigos de Desmodus rotundus, com monitoramento pelo menos uma vez por ano, respeitando as características regionais de cada estado. A estratégia de vigilância epidemiológica e o plano de trabalho adotado devem ser revisados anualmente ou sempre que necessário. A elaboração de medidas profiláticas certamente trará resultados positivos, mediante as recentes exposições ao vírus ${ }^{15}$.

Um grande e importante instrumento de vigilância epidemiológica é a tipificação antigênica pela imunofluorescência indireta (IFI) usando AcM, que é uma
A Região Norte

foi a segunda região com mais notificações (77) no período estudado. A falta de informações, saneamento básico

e uma estrutura

inadequada de

saúde, contribuíram

para os surtos. $\mathrm{O}$

predomínio de

casos na zona rural,

provavelmente

devido a surtos

com exposição

aos morcegos

D. rotundus na

Amazônia brasileira

em 2006 e 2009 técnica específica rápida, e a caracterização genética por RT-PCR e sequenciamento nucleotídico 16 também a heminested-RT-PCR (hnRT -PCR) tem sido empregada obtendo-se boa sensibilidade e especificidade, confirmando o diagnóstico da IFD em curto período de tempo ${ }^{17,18}$. As pesquisas efetuadas com base na biologia molecular tem sido relevante importância, não só para complementar os conhecimentos sobre a patogênese e a imunologia da infecção rábica, como também, para a determinação da variabilidade genética do VRab, inclusive entre cepas e ainda para o esclarecimento dos mecanismos de replicação e transmissão viral ${ }^{19}$.

Todo caso humano suspeito de raiva é de notificação compulsória e imediata nas esferas municipal, estadual e federal. A notificação deve ser registrada no Sistema de Informação de Agravos de Notificação (Sinan), por meio do preenchimento e envio da Ficha de Investigação da Raiva ${ }^{20}$. Apesar da cura de um paciente com raiva em ${ }^{21,22,23}$ mostrou que há possibilidades de tratamento da doença, a profilaxia antirrábica humana correta e oportuna, continua sendo o meio mais eficiente para evitar óbitos humanos devido à doença ${ }^{24}$. Visto isso, ainda há uma certa fragilidade no controle da raiva humana na região Norte, pois, existe uma certa debilidade realização das notificações compulsórias que são feitas há nível municipal, dificultando assim as ações do Ministério da Saúde. Além disso, há poucas revisões bibliográficas epidemiológicas da raiva humana na região Norte, a qual foi realizada o presente estudo.

\section{CONCLUSÃO}

Dessa forma, este estudo permitiu reforçar a apresentação do vírus da raiva humana de forma endêmica, com surtos esporádicos que podem estar relacionados a fatores como clima, temperatura, assim como as modificações contínuas do espaço urbano. Os resultados apresentados permitem observar que, em face da complexidade dos processos epidemiológicos, a compreensão acerca da ocorrência de 
surtos em regiões favoráveis, tornam-se um grande desafio para a vigilância e o controle de vetores, uma vez que a raiva humana, caracteriza-se como um grave problema de saúde pública, sobretudo em áreas isoladas onde o índice de pobreza é elevado, além da falta de informação e saneamento básico, o que contribui para o agravamento na região norte. Além disso, uma provável causa para a propagação da doença é o crescente desmatamento nas regiões afetadas, facilitando o contágio com seres humanos e outros animais. Entre os desafios a serem enfrentados, destacam-se a necessidade de otimização no controle da doença por meio do incentivo à adoção de recursos regulatórios e preventivos nas ações de vigilância e controle da raiva.

\section{REFERÊNCIAS}

1. Brasil. Ministério da Agricultura, Pecuária e Abastecimento. Controle da raiva dos herbivoros : manual técnico 2009 / Ministério da Agricultura, Pecuária e Abastecimento. Secretaria de Defesa Agropecuária. - Brasília : Mapa/ACS, 2009. 124 p. ; $18 \mathrm{~cm}$.

2. Who - World Health Organization. Expert Consultation on Rabies: First Report (WHO Technical Report Series). Geneva, Switzerland: World Health Organization, 2004, n. 931, 121 p.

3. Chalmers, A.W.; SCOTT, G.R. Ecology of rabies. Tropical Animal Health and Production, v. 1, p. 33-55, 1969.

4. Chorino, N, C. Caracterização molecular e filogenética de isolados do vírus rábico (lyssavirus - rhabdoviridae) em espécimes clínicos de herbívoros no estado do Rio de Janeiro. Tese. Centro de Ciências e Tecnologias Agropecuárias da Universidade Estadual do Norte Fluminense Darcy Ribeiro. Rio de Janeiro. 2009.

5. Schneider MC, Souza LM, Moraes NB, Diaz RC. Controle da raiva no Brasil de 1980 a 1990. Revista de Saúde Pública. 1996; 30(2):196-203.

6. Belotto A, Leanes LF, Schneider MC, Tamayo H, Correa E. Overview of rabies in the Americas. Virus Research. 2005; 111(1):5-12.

7. Schneider MC, Belotto A, Adé MP, Hendrickx S, Leanes LF, Rodrigues MJF, et al. Current status of human rabies transmitted by dogs in Latin America. Cadernos de Saúde Pública. 2007; 3(9):2049-2063.

8. Melo-Filho DJ. Reorganização das práticas e inovação tecnológica na vigilância em Saúde e os 20 anos do SUS. Texto elaborado como subsídio à sistematização do Relatório da SVS (Gestão 2007-2008). Brasília: Ministério da Saúde; 2008. 10. Laguardia J, Domingues CMA, Carvalho C, Lauerman CR, Macário E, Glatt R. Sistema de Informação de Agravos de Notificação (Sinan): desafios no desenvolvimento de um sistema de informação em saúde. Epidemiologia e Serviços de Saúde. 2004; 13(3):135-147.

9. Brasil. Ministério da Saúde. Secretaria de Vigilância em Saúde. Departamento de Vigilância Epidemiológica. Doenças infecciosas e parasitárias: guia de bolso, $8^{a}$ edição. Brasília: Ministério da Saúde, 2010.

10. Silva, R, R. Bacha, C, J, C. Acessibilidade e aglomerações na Região Norte do Brasil sob o enfoque da Nova Geografia Econômica. Nova Economia. Belo Horizonte_24 (1) 169-190.

11. Rosa EST, Kotait I, Barbosa TFS, Carrieri ML, Brandão PE, Pinheiro AS, et al. Bat-transmitted human rabies outbreaks, Brazilian amazon. Emerg Infect Dis [Internet]. 2006 Aug [cited 2019 Feb 26];12(8):1197-202.

12. Mendes WDS, Silva AAM, Neiva RF, Costa NM, Assis MS, Vid- igal PMO, et al. An outbreak of bat-transmitted human rabies in a village in the Brazilian Amazon. Rev Saúde Pública [Internet]. 2009 Dec [cited 2019 Feb 26];43(6):1075-7.

13. Novais, B. A. F., \& Zappa, V. (2008). Raiva em bovinos-revisão de literatura. Revista Científica Eletrônica de Medicina Veterinária Da Faculdade de Medicina Veterinária e Zootecnia de Garça, 10.

14. Alves, Thiago Willame Barbosa et al.. "Perfil de acometidos por raiva humana no nordeste brasileiro entre os anos de 2001 a 2017: um estudo documental". Anais CONADIS... Campina Grande: Realize Editora, 2018. Disponível em: <https://editorarealize.com. br/artigo/visualizar/50800 >. Acesso em: 23/10/2020.

15. Brasil. Ministério da Agricultura, Pecuária e Abastecimento. Controle da raiva dos herbívoros : manual técnico 2009 / Ministério da Agricultura, Pecuária e Abastecimento. Secretaria de Defesa Agropecuária. - Brasília : Mapa/ACS, 2009.

16. Brasil. Ministério da Saúde. Raiva in: Guia de vigilância epidemiológica / Ministério da saúde, Secretaria de Vigilância em Saúde. 6. ed. -Brasília, 2005. 603-632.

17. Araújo, D, B. Langoni, H. Almeida, MF, Megid, J. Heminested reverse-trancriptase polymerase chain reaction (hnRT-PCR) as a tool for rabies vírus detection in stored and decomposed samples. BMC Research Notes, 2008 1:17,.

18. Heaton, P. R.; Johnstone, P.; Mcelhinney, L.M.; Cowley, R.; O'sullivan, E.; Whitby, J.E.. Heminested PCR assay for detection of six genotypes of rabies and rabies-related viruses. Journal of Clinical Microbiology.Vol. 35, n. 11, nov. 1997, 2762-2766.

19. Wunner, W.H.; Larson, J.K.; Dietzschold, B.; Smith, C.L. The molecular biology of rabies viruses. Reviews of Infectious Diseases, 10: 771-84.

20. Kotait, I., Takaoka, N.Y., Carrieri, M.L., 2009: Manual Técnico Instituto Pasteur. Raiva - Aspectos gerais e clínica. São Paulo: Instituto Pasteur.

21. Wada, M. Y., S.M. Rocha, A.N.S. Elkhoury, 2011: Situação da Raiva no Brasil 2000 a 2009, Epidemiol. Serv. Saúde, Brasília, outdez;20 (4):509-518.

22. Ministério da Saúde, 2009b: I Protocolo para Tratamento de Raiva Humana no Brasil. Secretaria de Vigilância em Saúde, Departamento de Vigilância Epidemiológica. Epidemiologia e Serviços de Saúde, 18 (4):385-394.

23. Bourhy, H., 2010: Rabies, still neglected after 125 years of vaccination. PLoS neglected tropical diseases, 11 (4): 839.

24. Bourhy, H., 2010: Rabies, still neglected after 125 years of vaccination. PLoS neglected tropical diseases, 11 (4): 83 